\title{
Study of Vision Problems in Schools in Libreville and Owendo, Gabon
}

\author{
Simon Ategbo ${ }^{*}$, Jean Koko', Edgar Brice Ngoungou'2, Eliane Kuissi ${ }^{1}$, \\ Christelle Moyou Tchapbou1, Steeve Minto'o1, Emmanuel Mve Mengome3, \\ André Moussavou ${ }^{1}$ \\ ${ }^{1}$ Pediatrics Department, Faculty of Medecine, Health Sciences University, Libreville, Gabon \\ ${ }^{2}$ Department of Epidemiology and Biostatistics, Faculty of Medecine, Health Sciences University, Libreville, \\ Gabon \\ ${ }^{3}$ Ophtalmology Department, Omar Bongo Ondimba Army Instruction Hospital, Libreville, Gabon \\ Email: sategbo@yahoo.fr
}

Received 7 November 2014; revised 3 December 2014; accepted 13 December 2014

Academic Editor: Carl E. Hunt, George Washington University School of Medicine and Health Sciences, USA

Copyright (C) 2014 by authors and Scientific Research Publishing Inc.

This work is licensed under the Creative Commons Attribution International License (CC BY). http://creativecommons.org/licenses/by/4.0/

(c) (7) Open Access

\begin{abstract}
The purpose of this work is to evaluate the epidemiological aspects of vision problems and their repercussions in the schooling of children in Libreville and Owendo. Methodology: This transversal and descriptive study was carried out in May and June 2011. Included in the study were children in the $7^{\text {th }}$ and $8^{\text {th }}$ grades of the primary schools in Libreville and Owendo. For each child, an eye exam, including the subjective measure of visual acuity, was carried out using the Monoyer scale, and the color vision assessment was carried out with the Ishihara test. Any visual capacity under or equal to $7 / 10^{\text {th }}$ in at least one eye was considered to be pathological. We gathered information about demographic characteristics, any preceding vision issues on the record, data on other medical problems on the record and the eye examination on computer cards. Results: Nine hundred and sixty-three children (416 boys and 517 girls, with a gender ratio of 0.86 ) were examined. The average age was $12 \pm 1.7$ years old. The prevalence of the drop in visual acuity was $16.2 \%$. The prevalence of color vision anomalies was $15.5 \%$. Complaints concerning vision problems were significantly more present from children with a drop in visual acuity $(p<0.01)$. Visual anomalies had an impact on the children's schoolwork, and yet, visits to the ophthalmologist's office were few. Conclusion: The frequency of anomalies in vision justifies systematic screening in schools and organization of an appropriate treatment.
\end{abstract}

\section{Keywords}

Visual Acuity, Children, Schools, Color Vision

\footnotetext{
${ }^{*}$ Corresponding author.

How to cite this paper: Ategbo, S., Koko, J., Ngoungou, E.B., Kuissi, E., Tchapbou, C.M., Minto'o, S., Mengome, E.M. and Moussavou, A. (2014) Study of Vision Problems in Schools in Libreville and Owendo, Gabon. Open Journal of Pediatrics, 4, 300-306. http://dx.doi.org/10.4236/ojped.2014.44041
} 


\section{Introduction}

Vision deficiency is a reduction in vision that can either exist from birth or may result from a disease or eye traumatism [1]. Over $90 \%$ of people with vision deficiencies in the world live in developing countries [2]. While the prevalence of vision problems is approximately 10 times less frequent among children than adults, children's visual deficiencies remain a high priority because of the number of years that they live with this handicap. It can interfere with the development of the child and have an impact on his motor, cognitive, and emotional competence and can even have an impact on his academic performance and, consequently, on his transition into the professional job market [3]. On a world scale, one of the most frequent causes of the drop in visual acuity among children is ametropia, or anomalies of refraction [3]. The prevalence of ametropia among children varies according to different studies and ranges from $2 \%$ to $30 \%$ according to the age group or the eye examination methodology. Drops in BAV are the primary cause of visits to the ophthalmologist by school children [4]. The reversibility of these problems depends not only upon their cause but also on early diagnosis and the age of the child when first treated [5]. This explains the necessity of setting up and making available simple, fast and reliable screening procedures. According to the recommendation of the American Academy of Pediatrics (AAP), early screening of visual problems and the measuring of visual acuity should be done starting at the age of three (3). In France, a study carried out by INSERM 2002 estimated that approximately 550,000 children aged 0 to 5 years old present with a visual impairment, $86.1 \%$ of whom present with ametropia, and $12.7 \%$ are predicted to have organic lesions [6].

In Gabon, very little data are available on the visual health of children, particularly among school children.

The purpose of this work is to evaluate the frequency of the drop in visual acuity and color vision anomalies, as well as their impact upon the schoolwork of children in Libreville and Owendo.

\section{Methodology}

\subsection{Type of Study}

This is a transversal and descriptive study that took place between May $2^{\text {nd }}$ and June $30^{\text {th }}, 2011$.

\subsection{Framework for the Study}

The setting of this study was Libreville, administrative and political capital of Gabon, and Owendo. The population of Gabon is 1517685 inhabitants. Libreville is a cosmopolitan city wich has a heterogenous population of 419,598 inhabitants, $40.8 \%$ of whom are children under the age of 15 . Owendo is the second city located to the South of Libreville, and has 70,000 inhabitants, 11,094 of whom are children under the age of 15 [7] [8]. The school attendance rate is $94 \%$. This study was carried out in the public and private primary schools of Libreville and Owendo.

\subsection{Study Procedures}

Based on the list of 350 establishments given to us by the Statistics Department of the Ministry of National Education, we selected participants using a simple random drawing of schools in these two communities. In each school, we retained the $7^{\text {th }}$ and $8^{\text {th }}$ grade classes.

\subsection{Criteria for Inclusion}

We included both genders in this study, and the inclusion criteria were as follows:

- 8 to 17 years old;

- Enrolled in $7^{\text {th }}$ and $8^{\text {th }}$ grade classes;

- Children with authorization from their parents to participate;

- Children who were present on the day of the survey.

\subsection{Criteria for Non Inclusion}

Only children fulfilling the age criteria but whose parents refused to allow them to take part of study.

Participant recruitment was performed by a medical team including an ophthalmologist, an epidemiologist and five medical students. After a training session and pre-testing, we gathered data using a standardized data file. This included the identity of the school; the age, gender and class of the students; their family vision records; 
their frequency of visits to the ophthalmologist; the visual, social and intellectual behavior of the child; the socio-economic characteristics of the parents; and the academic level of the mother.

For each child, a clinical examination was carried out, allowing for the verification of the position of the head, the appearance of the eyelids, the symmetry of the eyeballs, the different parts of the eye and ocular follow-up.

\subsection{Measuring Visual Acuity and Color Vision}

Visual acuity involves measuring the long distance visual acuity in each eye, as well as in both eyes with and without a glass using the Monoyer scale graduated in tenths and placed $5 \mathrm{~m}$ from the child. This scale was preferred to the Snellens Chart since it was better adapted to school children and general public studies. Visual acuity of 10 over 10 was considered normal. Visual acuity under or equal to 7 over 10 in at least one eye was considered to be pathological. To quantify the severity of the vision impairment, we defined having a visual acuity of $\leq 3$ over 10 as low vision compared to visual acuity between 4 and 7 over 10 .

The examination of color vision was done using the Ishihara album.

\subsection{Ethical Considerations}

The study was carried out in compliance with the Clinical Best Practices Guide and the Regulations of the Ministry of Public Health. We obtained approval from the Ministry of Education and the Directors of the Primary Schools.

\subsection{Statistical Analysis}

Data collection was conducted using EPI DATA 3.1 Software. The statistical analysis was performed using Statview 5.0 Software. The comparison between qualitative variables was performed using the chisquared test, and the quantitative variables were compared using Student's t-test. The threshold for the definition of "significance" was set at $5 \%$. On the basis of the frequency of $14.3 \%$ of vision impairment in children [9], with a risk $\alpha$ at $5 \%$ and $\beta$ at $20 \%$, the number of subjects required was calculated to be 1046 .

\section{Results}

A total of 1346 children were asked to participate in this study. Among them, 963 received parental approval, representing a $71.5 \%$ participation rate. The characteristics of those participating in the study are presented in Table 1. The proportion of children complaining about their vision was $66.2 \%(n=634)$. This included frequent headaches (20.6\%), photophobia or abnormal sensitivity to light (13.4\%), tearing of the eyes (43.9\%) and ocular itching (43.9\%) (Figure 1).

Table 1. General characteristics of the population.

\begin{tabular}{ccc}
\hline & Number (N = 963) & Percentage \\
\hline Gender & & 46.3 \\
Boys & 416 & 53.7 \\
Girls & 517 & 36.9 \\
Age Groups (years) & & 55.3 \\
$8-12$ & 355 & 7.8 \\
$12-15$ & 533 & 39.3 \\
$>15$ & 75 & 60.9 \\
Year in School & & 28.1 \\
$7^{\text {th }}$ Grade & 378 & 71.9 \\
$8^{\text {th }}$ Grade & 585 & 7.2 \\
Family History of Vision Problems & & 92.8 \\
Present & 271 & \\
Absent & 692 & \\
\hline
\end{tabular}




\subsection{Visual Acuity Clinical Data}

Among the 963 children examined, 156 children (16.2\%) 95\% CI [13.9\% - 18.5\%] had pathological visual acuity. The average age was $12 \pm 1.6$ years (range: 8 - 15 years). In this group, 38 children (24.4\%) $95 \%$ CI [17.7\% $-31.1 \%$ ] had a visual acuity of 3 or less over $10(\mathrm{VA} \leq 3 / 10)$ in at least one eye. The characteristics of children with suboptimal visual acuity are summarized in Table 2.

Out of all the children with impaired visual acuity, the number repeating the school year was as expected: 1.2 \pm 0.9 . We did not observe a significant link between visual acuity impairment and the number of children repeating their year in school (Table 3). Nevertheless, for 48.7\% $(n=80)$ of the children presenting with visual acuity impairment, according to the observations of their parents, their schoolwork was acceptable, although a significant link was identified between visual acuity impairment and academic performance.

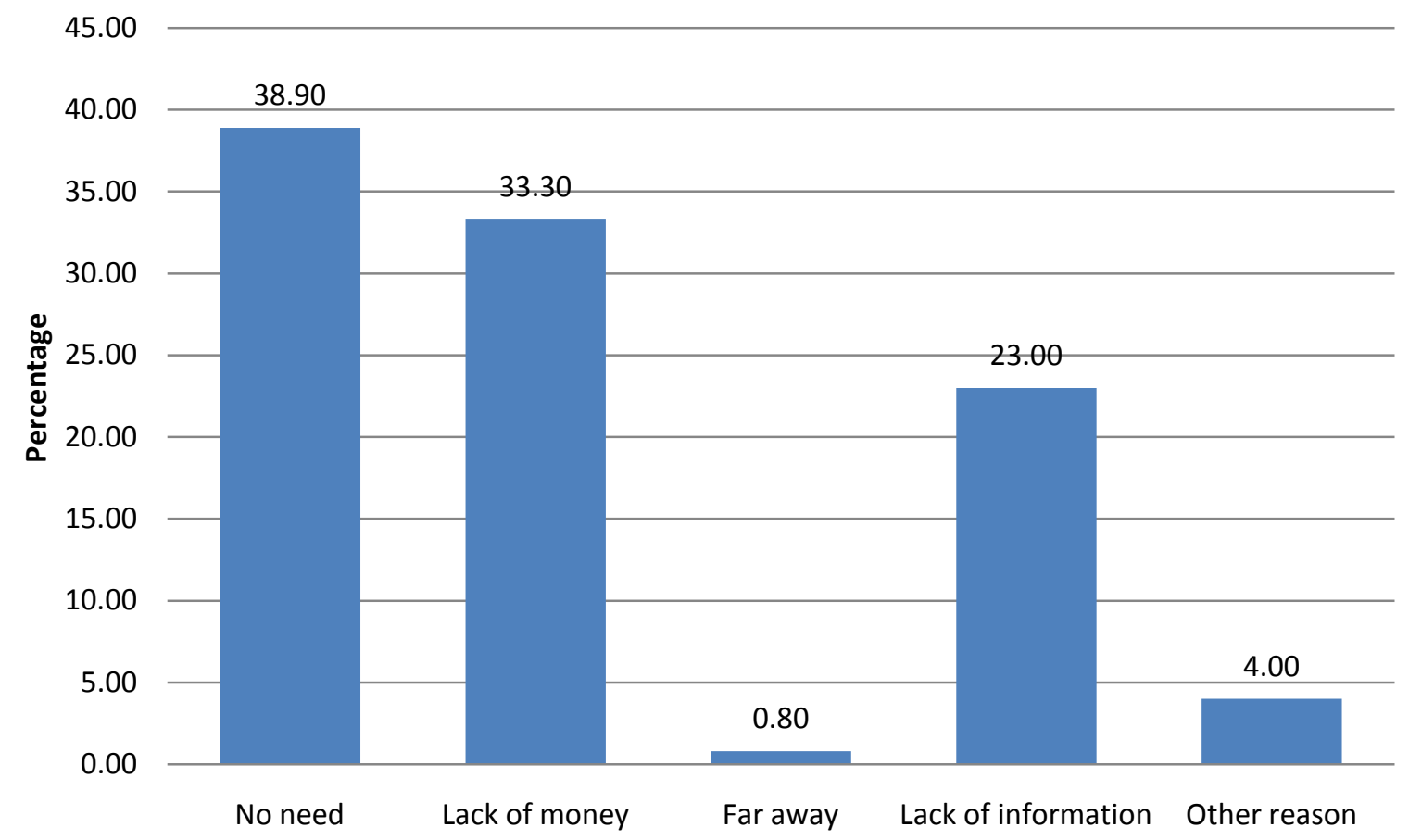

Figure 1. Distribution of children with visual acuity impairment according to the reasons for not consulting an ophthalmologist.

Table 2. Characteristics of children with visual acuity impairment.

\begin{tabular}{ccc}
\hline Gender & Number $(\mathbf{N}=\mathbf{1 5 6})$ & Percentage \\
Boys & 57 & 36.5 \\
Girls & 92 & 63.5 \\
Age Groups (Years) & & 41.0 \\
$8-12$ & 64 & 51.3 \\
$12-15$ & 80 & 7.7 \\
$>15$ & 12 & 37.2 \\
Year in School & & 62.8 \\
$7^{\text {th }}$ Grade & 58 & 6.7 \\
\hline
\end{tabular}


Table 3. Distribution of visual acuity impairment by failure in school.

\begin{tabular}{ccccc}
\hline \multirow{2}{*}{ Number of Students Who Repeat School Years } & \multicolumn{2}{c}{ Visual Acuity $\leq \mathbf{7 / 1 0 ^ { \text { th } } \mathbf { 8 } - \mathbf { 1 0 } / \mathbf { 1 0 }}$ th } & Total \\
\cline { 2 - 4 } & $\mathbf{n}(\mathbf{\%})$ & $\mathbf{n}(\mathbf{\%})$ & $172(17.6)$ & 173 \\
$\mathbf{0}$ & $31(19.9)$ & $655(81.2)$ & 776 \\
$\mathbf{1}$ to $\mathbf{3}$ & $121(77.6)$ & $10(1.2)$ & 14 \\
Total & $4(2.6)$ & $807(100)$ & 963 \\
\hline
\end{tabular}

Concerning previous personal medical records of the children presenting with impaired visual acuity, 18 were born prematurely (11.5\%), whereas 138 (88.5\%) were full-term births. Among the 156 children with visual acuity impairment, six children (3.8\%) wore glasses. They had a visual acuity between 4 and 7 over 10 in at least one eye. Within this group of children with impaired visual acuity, 58 of them (37.2\%) had parents with vision problems. We observed a significant association between visual acuity impairment among the children with a family history of visual problems $(\mathrm{p}<0.01)$.

Among the 156 children with visual problems, 126 of them (80.8\%) had never been to see an ophthalmologist. Only 30 of them (19.2\%) had been previously examined at least once by an ophthalmologist. A significant association was found between visual problems and visits to see the ophthalmologist $(\mathrm{p}<0.01)$. Various reasons were given for the absence of visits to the ophthalmologist (Illustration $\mathrm{N}^{\circ} 1$ ). Seventeen children (56.7\%) had been examined by an ophthalmologist in the past 2 years, 12 children had been examined by an ophthalmologist in the past 2 to 5 years, and 3.3\% $(n=1)$ of the children could not remember their last visit. Ninety-one children (58.3\%) watched television up close to the screen.

The frequency of the visual complaints described by the children presenting with visual acuity impairment was $88.5 \%(n=138)$. Tearing was described by $66.7 \%$ of the children $(n=104)$, ocular itching was described by $59.6 \%$ of the children $(n=93)$, frequent headaches were described by $25.6 \%$ of the children $(n=40)$, and photophobia was described by $26.3 \%$ of the children $(n=41)$. Moreover, sometimes several complaints were made by the same child.

\subsection{Color Vision Clinical Data}

Out of the 963 children examined, 149 of them (15.5\%) 95\% CI [13.2\% - 17.8\%] presented with an anomaly in color vision. The average age was $12.6 \pm 1.7$ years. They were divided into 60 boys (40.3\%) and 89 girls (59.7\%). We did not observe any significant association between color vision anomalies and those who had to repeat their school year, nor was there any significant connection between having a family history of vision problems and color vision anomalies.

If we consider children with impaired visual acuity, $15.4 \%(n=24)$ also had a color vision anomaly, as opposed to $84.6 \%(n=132)$ of the children who had normal color vision. We did not find a statistically significant association between visual acuity impairment and color vision anomalies.

\section{Discussion}

This study is the first significant study of this kind to be performed in Gabon in the school environment. The participation rate in this study was 71.5\% and was close to that of Maul et al. in Chile, which was 75.8\% [10], and that of Yehouessi et al. in Benin, which was 63.4\% [11]. We have evaluated visual acuity impairment and color vision anomalies. All of the children benefited from subjective measuring of visual acuity using the Monoyer scale and the color vision examination using the Ishihara Test, as recommended by Madhu Gupta et al. in the North of India [12]. Subjective measuring of visual acuity would appear to be less specific and less sensitive; nevertheless, it is a common method for screening in schools and is affordable, accessible and less complicated compared to objective measuring with a cycloplegia [4] [10]. The threshold for detecting visual deficits selected for our study was visual acuities $\leq 7$ over 10 in at least one eye. For the study concerning the screening of visual problems in Hauts-de Seine, children aged 3 to 5 were directed to the ophthalmologist when their distance visual acuity was $\leq 7$ over 10 . This threshold was also used for the work of Roche J. et al. in Mayotte [13] and Auze- 
mery A. et al. in Antananarivo [14]. Khandekar R. et al. retained a threshold of 5 over 10 in each eye [15].

We examined 963 children, of whom $46.3 \%$ were boys and $53.7 \%$ were girls (the gender ratio was 0.86 ). This ratio is similar to that described by Ayed et al. who found that the gender ratio was 0.84 with more girls [4]. This might be due to the higher school attendance rate of girls compared to boys in Gabon. The average age in our group of children was $12 \pm 1.7$ years; $16.2 \%$ of the children aged 8 to 17 years presented with visual acuity impairment. In the Southwest of Nigeria, among children under the age of 15 , the prevalence of problems in visual acuity was 14.3\% [9], whereas in Benin, it was 9.2\% among children aged 6 to 9 years old [11]. In Paris, the prevalence of visual acuity impairments was $16.5 \%$ among children in kindergarten [16]. Other studies carried out in schools found higher percentages of visual acuity impairment than our study: $22 \%$ in the North of India [12], 43.1\% in Cameroon [17], and 57.2\% in Tunisia [4]. This disparity in the prevalence of refractive errors can be explained by several factors: the variability in the screening methods and the recruitment of different study populations (prospective studies in schools and retrospective studies in hospitals), the age group under study, ethnic variations, racial and genetic differences, and socio-economic levels. In our study, we found no significant connection between age and visual problems. Among school children in poor neighborhoods in Tunis, $60 \%$ to $65 \%$ of the ametropia cases were between 8 and 11 years old [4]. In the North of India [12], the prevalence of refractive errors increased significantly after the age of 10 in a private school. We found a higher frequency of visual acuity problems among girls than boys. Other authors have reported a higher frequency of hypermetropia among girls [18] [19] or myopia among boys [20]. No physio-pathological explanation could be identified.

Concerning family history records, we identified a connection between visual acuity impairment and the presence of visual pathology among brothers or parents of the children included in the study. Roche [13], in a randomized study in Mayotte, found a hereditary characteristic of the anomalies of refractions observed. In a study in Paris on the screening of vision anomalies among preschool children, 33\% of the fathers and $41 \%$ to $43 \%$ of the mothers had ocular pathologies [16]. Visual complaints are frequent among children with visual acuity impairments. Tearing, ocular itchiness and headaches were described by other authors [10] [11] [21].

Vision problems have a direct impact on academic outcomes. Ayed et al. emphasized the fact that cases of ametropia, regardless of the type, are highly associated with academic retardation, although other social and economic factors can intervene [4]. Similarly, these children adjust to bad vision by sitting near the blackboard, getting up close to the television, or by holding books closer to their eyes [12]. These different signs should attract the attention of parents and lead them to take their child to see the ophthalmologist.

None of the children who presented with severe visual acuity impairments had ever been examined or assisted. This is due to the children's ignorance about the anomaly and also the lack of attentiveness on the part of the parents when faced with the complaints of the children. Likewise, going to see the ophthalmologist was a rare event based on the reasons previously mentioned, including the absence of need, the absence of financial means and the distance to be traveled; all of these factors are indicative of the problems we face when trying to take care of children's visual deficits in our context.

The prevalence of color vision problems was 15.5\%. These figures are higher than those reported in Mayotte (0.2\%) among 5-year-old children [13] or in the North of India (2.3\%) among children 6 to 16 years old [12]. This might be due to problems in comprehension and poor readings of the Ishihara test by certain students, which certainly may have led to some false positive readings.

\section{Conclusion}

Visual problems (visual acuity impairment and color vision anomalies) are frequent in Gabonese schools with a consequential impact on academic performance and on the children's social life. Vision problems are rarely treated, and this has led us to conclude that we must have systematic screening. In our context, the early screening of refraction anomalies in the school environment can be done by a subjective method based on the Monoyer Scale; in case of anomalies, children can benefit from an automatic refractometer with or without a cycloplegia with an eye specialist for the purpose of identifying the type of refraction problems.

\section{Declaration of Interest}

The authors hereby declare that they have no conflict of interest concerning this article. 


\section{References}

[1] Keeffe, J. (1995) L’évaluation de la baisse vision dans les pays en développement: Le dépistage de la déficience visuelle; OMS programme de prévention de la cécité et Low vision project International; WHO/PBL/95.48.

[2] OMS (2006) Initiative mondiale pour l'élimination de la cécité évitable. Plan d’action 2006-2011. Report of a WHO working Group Geneva, 2002 (WHO/PBH/03.92). ISBN 9789242595888.

[3] Kraiem, A., Trojet, S., Kasrl, A. and Elafrit, M.A. (2006) Les déficiences visuelles chez l'enfant. Santé Tunisie, 1-7.

[4] Ayed, T., Sokkah, M., Charfi, O. and El Matri, L. (2002) Epidémiologie des erreurs réfractives chez des enfants scolarisés, socio-économiquement défavorisés en Tunisie. Journal Français d'Ophtalmologie, 2, 712-717.

[5] Bois, C., Binot, M.C., Jonqua, F., Guillemot, G. and Bremond-Gignac, D. (2007) Dépistage des troubles visuels entre 3 et 5 ans: Expérience du service départemental de la Protection Maternelle et Infantile dans les Hauts-de-Seine. Journal Français d'Ophtalmologie, 30, 570-576. http://dx.doi.org/10.1016/S0181-5512(07)89660-4

[6] Les atteintes sensorielles chezl'enfant. DGS/GTNDO. www.eps-polelorraine.fr/actions/S0004/docs/observation_locale/rapport_gtndo.pdf

[7] Gabon. Direction Générale de la statistique et des Etudes Economiques: Ministère du Développement, de la Performance Publique, de la Prospective et de la Statistique 2009. www.stat-gabon.org

[8] Gabon. Archives du Ministère de l'Education Nationale, 2000.

[9] Onakpoya, O.H. and Adeoye, A.O. (2009) Childhood Eye Diseases in Southwesten Nigeria: A Tertairy Hospital Study. Clinics (Sao Paulo), 64, 947-952.

[10] Maul, E., Barrosso, S., Munoz, S.R., Sperduto, R. and Ellwein, L.B. (2000) Refractive Error Study in Children: Results from La Florida, Chile. American Journal of Ophtalmoogy, 129, 445-454.

[11] Odoulami-Yehouessi, L., Tchabi, S., Sounouvou, I., Deguenon, J., Doutetien, C. and Basssabi, S. (2005) La réfraction de l'enfant scolarisé au CNHU de Cotonou. Mali Medical, 20, 24-27.

[12] Gupta, M., Bhupinder, P., Chauhan, A. and Bhardwaj, A. (2009) Ocular Morbidity Prevalence among School Children in Shimla, Himachal, North India. Indian Journal of Ophtalmology, 57, 133-138.

[13] Roche, J.J. (2005) Evaluation des handicaps visuels des enfants de cinq ans d’âge à Mayotte, étude prospective sur 2849 enfants en l'an 2000. Médecine Tropicale, 65, 465-472.

[14] Auzemery, A., Andriamanamihaja, R. and Boisier, P. (1995) Enquête sur la prévalence et les causes des affections oculaires chez les enfants des écoles primaires d'Antanarivo. Cahiers santé, 5, 163-166.

[15] Padhye, A.S., Khandekar, R., Dhamadhikari, S., Dolek, D., Gogate, P. and Deshpande, M. (2009) Prevalence of Uncorrected Refractive Error and Other Eye Problems among Urban and Rural School Children. Middle East African Journal of Ophtalmology, 16, 69-74.

[16] Tabone, M.D., Vincelet, C., Leclerq, J.P. and Clogenson, M.F. (2000) Dépistage des anomalies de la vision à l’âge préscolaire: Expérience du centre de bilans de santé de l’enfant de Paris. Archives dePédiatrie, 7, 1274-1283. http://dx.doi.org/10.1016/S0929-693X(00)00143-3

[17] Eballe, A.O., Bella, L.A, Owono, D., Mbome, S. and Mvogo, C.E. (2009) La pathologie oculaire de l'enfant âgé de 6 à 15 ans: Etude hospitalière à Yaoundé. Santé, 19, 61-66.

[18] Jeddi, A., Ben Hadj Alouane, W., Hammoud, M., Malouch, N., Zghal, I., Ayed, S. and Zouari, B. (2002) Apport de la correction totale après cycloplégie dans les céphalées. Journal Français d'Ophtalmologie, 25, 270-273.

[19] Zhao, J., Pan, X., Sui, R., Munoz, S., Sperduto, H.D. and Ellwein, L.B. (2000) Refractive Error Study in Children: Results from Shunyi District, China. American Journal of Ophtalmology, 129, 427-435. http://dx.doi.org/10.1016/S0002-9394(99)00452-3

[20] Ebana Mvogo, C., Bella-Hiag, A.L., Ellong, A., Metogo Mbarga, B. and Litumbe, N.C. (2001) Les amétropies statiques du noir camerounais. Ophtalmologica, 215, 212-216. http://dx.doi.org/10.1159/000050861

[21] Ebana Mvogo, C., Ellong, A., Bella, A., Luma, H. and Nyame, E. (2007) Les céphalées dans les amétropies. Médecine d'Afrique Noire, 54, 157-160. 
Scientific Research Publishing (SCIRP) is one of the largest Open Access journal publishers. It is currently publishing more than 200 open access, online, peer-reviewed journals covering a wide range of academic disciplines. SCIRP serves the worldwide academic communities and contributes to the progress and application of science with its publication.

Other selected journals from SCIRP are listed as below. Submit your manuscript to us via either submit@scirp.org or Online Submission Portal.
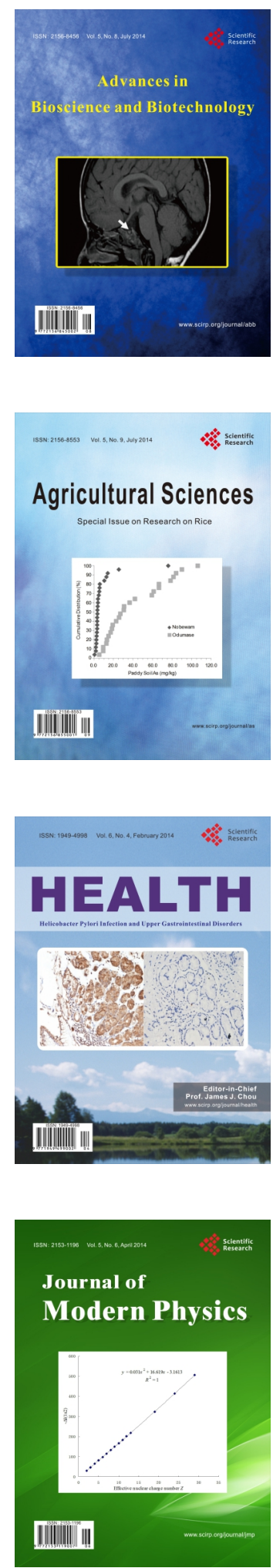
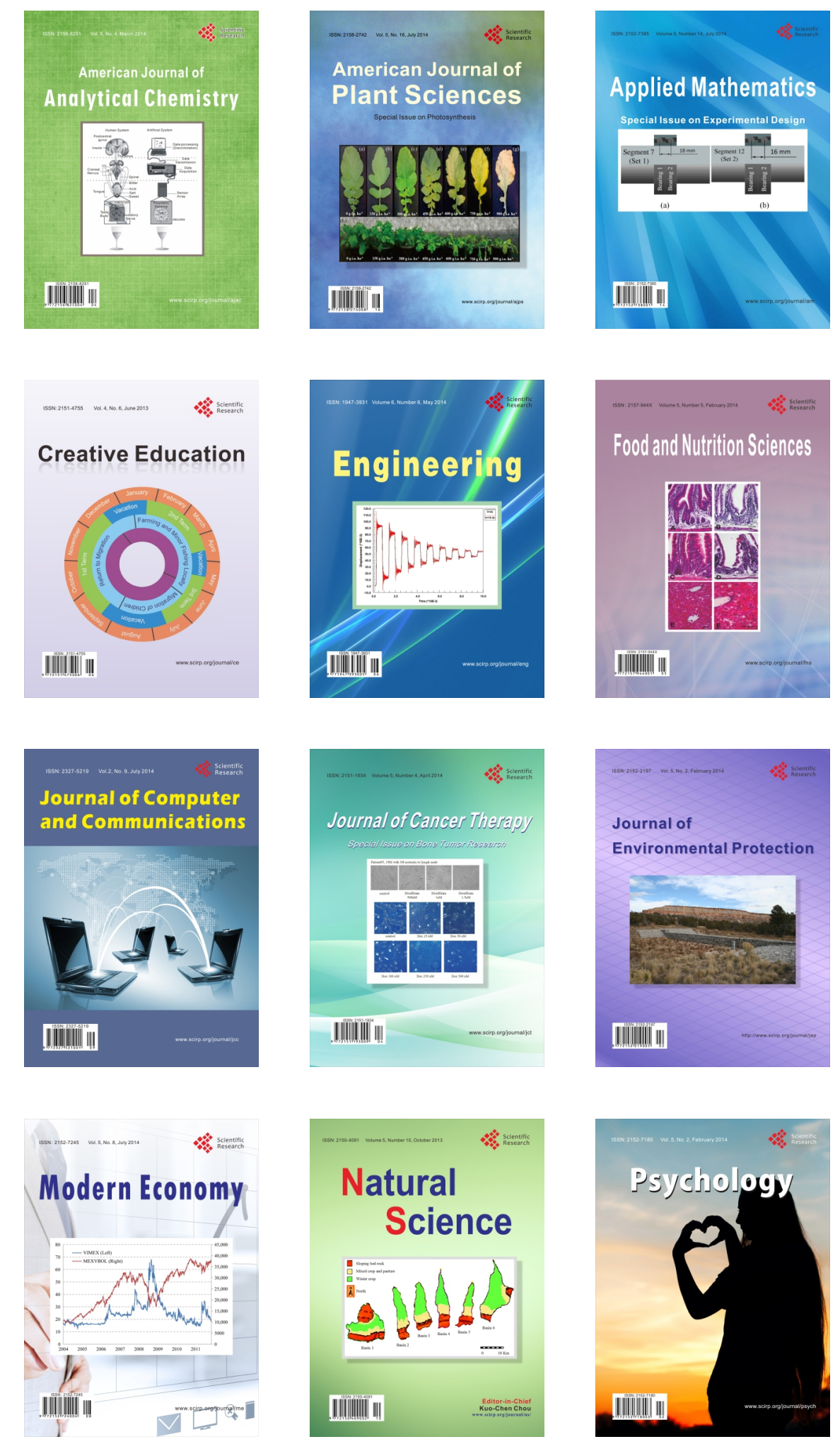